\title{
Work based concerns and personal implications of COVID-19
}

\author{
Namita Mathews ${ }^{1} \cdot$ George Moussa $^{1} \cdot$ Nonavinakere Manjunatha ${ }^{1}$
}

Received: 19 May 2020 / Revised: 21 June 2020 / Accepted: 23 June 2020 / Published online: 6 July 2020

(c) The Royal College of Ophthalmologists 2020

\section{To the Editor:}

In response to 'Survey of ophthalmology practitioners in $\mathrm{A} \& \mathrm{E}$ on current COVID-19 guidance at three major UK Eye Hospitals' [1].

We read the above article with interest and present our own ophthalmic departmental findings in a tertiary referral centre. The World Health Organisation declared COVID-19 a global pandemic on 11th March 2020 [2]. Since the emergence, significant changes have occurred including deployment of Ophthalmologists to medical wards and changes in the delivery of routine care. Furthermore, eye examinations and procedures involve close proximity with our patients, hence ophthalmologists are potentially more prone to contracting the virus. However, our examination still falls under the category of only requiring minimal personal protective equipment (PPE).

We conducted a departmental, self-administered paper survey amongst Ophthalmology doctors of varying grades to assess concerns associated with COVID-19 and personal implications of the pandemic between 13th and 17th April 2020. Sixteen ophthalmologists responded including six consultants (38\%), five ST3-7 (31\%), and five SAS doctors $(31 \%)$. Ninety-four percent of responders were not required to self-isolate till the point of data evaluation. Thirty-one percent of responders were living with vulnerable people and $44 \%$ had young children requiring supervision. Of the doctors with young children, $44 \%$ had to make new childcare arrangements. The majority (75\%) of respondents felt more stressed at work since the outbreak. The two major
Fig. 1 A pie chart to show the various concerns raised by staff. Each category represents the number of doctors out of 16 participants that shared that specific concern.

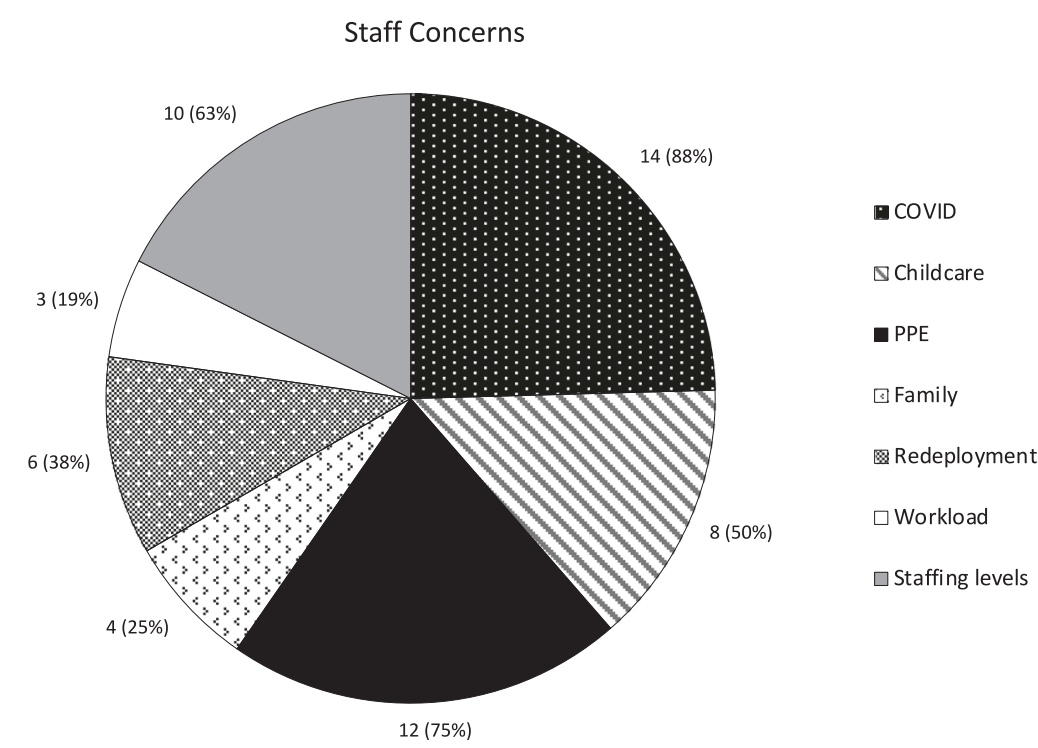

Nonavinakere Manjunatha

nonavinakere.manjunatha@uhcw.nhs.uk
University Hospitals Coventry and Warwickshire NHS Trust, Clifford Bridge Rd, Coventry CV2 2DX, UK 
Fig. 2 A bar chart to show the availability of various PPE in review of asymptomatic and suspect/COVID positive patients. Each bar represents each type of PPE that was available for use to doctors as reported when reviewing patients.

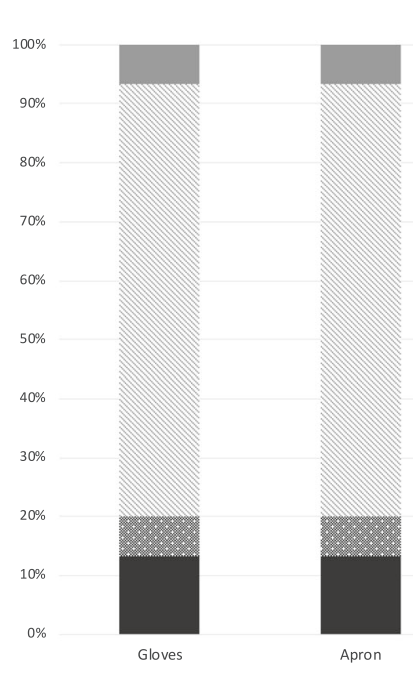

PPE available at work place

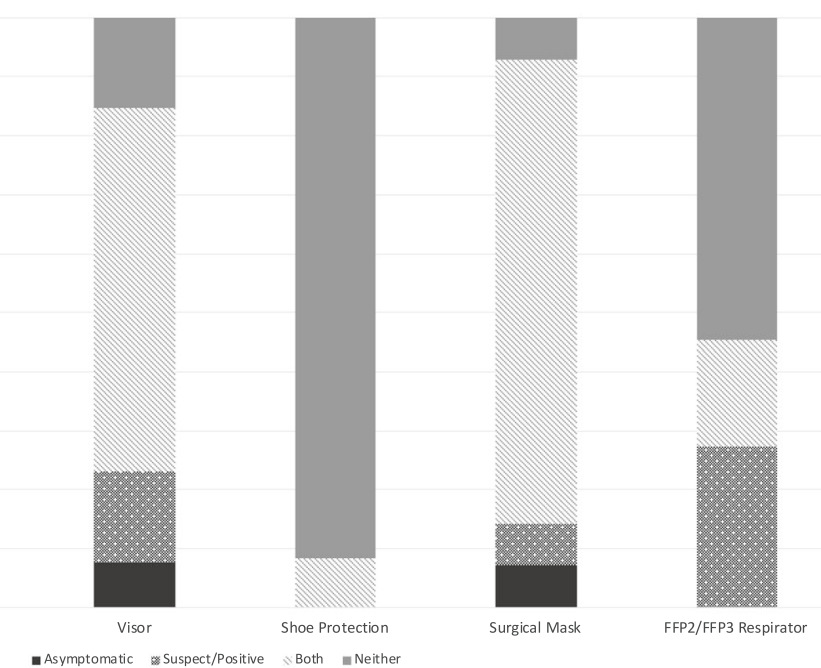

concerns raised were the risk of contracting COVID and PPE (Fig. 1). There was general consensus that gloves, visor, and apron were provided for review of asymptomatic and symptomatic/COVID positive patients. Thirty-six percent reported that they were not provided with an FPP3/ FFP2 mask for review of a suspect/positive patient (Fig. 2). The variety of responses to PPE availability reflect the confusion regarding PPE guidance in addition to the anxiety of increased exposure from close-proximity examinations.

Our survey demonstrates the undermined impact of COVID-19 on work-life balance of Ophthalmologists and the ongoing concerns of PPE. We continue to provide emergency care in the midst of staff shortages due to sickness and redeployment. Departmental contingency plans and rotas need to account for these aforementioned factors that can otherwise cause significant distress.

\section{Compliance with ethical standards}

Conflict of interest The authors declare that they have no conflict of interest.

Publisher's note Springer Nature remains neutral with regard to jurisdictional claims in published maps and institutional affiliations.

\section{References}

1. Minocha A, Sim SY, Than J, Vakros G Survey of ophthalmology practitioners in A\&E on current COVID-19 guidance at three Major UK Eye Hospitals. Eye. 2020. http://www.ncbi.nlm.nih.gov/pubmed/ 32265510.

2. Anon. WHO Director-General's opening remarks at the media briefing on COVID-19-11 March 2020. 2020. https://www.who. $\mathrm{int} / \mathrm{dg} / \mathrm{speeches} /$ detail/who-director-general-s-opening-remarks-atthe-media-briefing-on-covid-19---11-march-2020. 